\title{
Improving Teaching Methodology in System Analysis and Design using Problem Based Learning for ABET
}

\author{
Sara Fatima \\ Department of Information Systems, Faculty of Computing and Information Technology, \\ King Abdulaziz University, Jeddah, Saudi Arabia. \\ Email: sfatima@kau.edu.sa \\ Salha Abdullah \\ Department of Information Systems, Faculty of Computing and Information Technology, \\ King Abdulaziz University, Jeddah, Saudi Arabia \\ Email:sbente@kau.edu.sa
}

\begin{abstract}
System Analysis and Design is an active field that demonstrates continuously new techniques and approaches to develop systems more effectively and efficiently. Teaching System Analysis and Design courses are thus quite challenging for many reasons, such as rapid changes in the environment, changes in the nature of technology, demands and needs of the industry and new market trends. These factors will have a direct effect on the students learning and their effectiveness in the place of work. This paper examines this trend and considers Problem Based Learning as the best methodology to respond to them. It will improve the students understanding of the concepts, ideas and thus enhance their learning experience. This paper also examines the level of achievements in the course learning outcomes as outlined by Accreditation Board for Engineering and Technology.
\end{abstract}

Index Terms - System Analysis and Design, Problem based learning, ABET, ACM, KSO, CLO, PEO.

\section{INTRODUCTION}

"Tell me, and I will forget.

Show me, and I may remember.

Involve me, and I will understand.”

According to the above famous dictum of Confucius, a person learns best when he/she is actively involved in the learning process. They are many learning methodologies that have been adopted down the years. One of them is Problem Based Learning (PBL). PBL is an approach, in which the learners first encounter the problem, followed by a systematic, student-centered inquiry process [1]. Student-centered learning environment makes the students more responsible for their own learning, and thus the students become active constructors rather than passive recipients of knowledge. Learning becomes an act of discovery as student examines the problem, research its background, analyze possible solutions, develop proposals and produce a final result. It thus develops greater understanding of the material since the students find the information for themselves and actively use this information to complete the tasks. PBL helps to raise the quality of education [2]. PBL creates a contextual, collaborative, and constructivist learning environment [3]. Group work is another important feature in most PBL programs. In group work, the tutor is present as a facilitator or guide [4]. PBL is extremely effective as a method for engaging students in their learning. This automatically leads to more discipline, and mastery of academic contents, among the students.

The problems in PBL are usually in the form of cases, narratives of complex, real-world challenges common to the discipline being studied. There is no right or wrong answer. Rather, there are reasonable solutions based on application of knowledge and skills deemed necessary to address the issue. The solution therefore, is partly dependent on the acquisition and comprehension of facts, but also based on the ability to think critically [5].

The later part of the paper is organized in the following way. Section II discusses various teaching methodologies used in the class room. Section III displays the importance of System Analysis and Design (SAD) course in IS curriculum. Section IV throws light on advantages of Problem Based Learning (PBL). Section $\mathrm{V}$ shows the various teaching methodologies used at King Abdulaziz University (KAU). Section VI and Section VII presents the structure of Accreditation Process and Information Systems Program at KAU. Section VIII displays how System Analysis and Design Course is being taught at KAU and how the CLO's are being achieved according to ABET criteria. Section IX presents the survey analysis for implementing $\mathrm{PBL}$ in SAD course. Section $X$ shows the survey results after implementing PBL in the class. Section XI proposes a framework for achieving maximum students success factor. Section XII discusses about the challenges that were faced during the implementation of PBL in the class and finally Section XIII the paper is concluded by discussing the benefits of applying PBL in the 
classroom

\section{TEACHING METHODOLOGIES}

There are many different educations methodologies developed over the years. Some of these are teachercentered and some are student-centered. However they have the same goal, and the goal is to provide students with the best education and knowledge as possible. They are many teaching methods available. These include lecture, discussion, cooperative learning, distance learning, demonstration, online learning, active learning, critical thinking, experiential learning, games/simulations, humor, inquiry-guided learning, mobile learning, team based learning, debate and many more [6].

\section{A. Lecture}

This is a traditional instructional strategy used in classrooms. Though it is still very effective method where the faculty member can address a large number of groups together and control the students, the main disadvantage is that the level of students understanding on a certain topic cannot be gauged and the students tends to forget the information quickly.

\section{B. Discussion}

There are different methods in which the faculty member can initiate discussions individually or in a group. Students can be asked questions on the previously explained topic, taken their comments or make themparticipate in the emerging trends and issues.

\section{Cooperative learning}

The term collaborative learning is often used as a synonym for co-operative learning when, in fact, it is a separate strategy that encompasses a broader range of group interactions such as developing learning communities, stimulating student-faculty discussions, and encouraging electronic exchanges [7].

\section{Distance learning}

Distance learning is defined as any form of teaching and learning in which the teacher and learner are not in the same place at the same time [8]. Many have experienced learning outside of a structured classroom setting such as through television, video conferencing and correspondence courses.

\section{E. Online learning}

Online learning is access to learning experiences via the use of some technology. This teaching methodology offers distance or correspondence courses over the internet. It improves access to educational opportunities for learners described as both nontraditional and disenfranchised. They cover a wide range of courses, audiences and prices. Online learning allows students to complete the course work from wide range of locations and remove the time restrictions to access the course lecture [9].

\section{F. Active learning}

Active learning is anything that is course related what a student does in the classroom other than passively listening to the instructor's lecture. It improves the student's understanding and retention of information are very effective [10].

\section{G. Critical thinking}

Critical thinking is a collection of mental activities that include the ability to intuit, clarify, reflect, connect, infer and judge. Critical thinking includes the component skills of analyzing arguments, making inferences using inductive or deductive reasoning, judging or evaluating, and making decisions or solving problems [11].

\section{H. Experiential learning}

This involves learning from experience or in simple words students learn from what they do. In this methodology knowledge is created by transforming experience. It is a theory that defines the cognitive processes of learning and it asserts the importance of critical reflection in learning [12].

\section{Games/simulations}

Games and simulations provide rich learning environment for the students. An effective game will help students understand concepts more quickly and remember them better than from a lecture. Few games are designed to teach students specific subjects, which help the students to expand their concepts, reinforce development [13]

\section{J. Humor}

Using humor in the classroom is essential and healthy for students of all ages. Laughing makes learning a lot more fun and also more interesting. Few instructors use humor in the classroom to motivate students, enhance group cohesion and defuse tense situation. Humor is an essential element in pers onal communication [14].

\section{K. Inquiry-guided learning}

Inquiry-based learning is a process where students are involved in their learning, formulate questions, investigate widely and then build new understandings, meanings and knowledge. This knowledge is new to the students and may be used to answer a question, to develop a solution or to support a position or point of view. This helps them to build effective research skills [15].

\section{Mobile learning}

The development in smart phones and tablet devices like iPad are increasing ways in which learning can be delivered to the learners. Mobile learning (m-learning) involves using handheld technologies (smart phones, tablets) to study and learn. With this methodology students can access study materials no matter where they are. It is very much beneficial for effective communication with in their peers and instructors. This 
methodology reaches unreachable students, but also provides freedom to learn at convenience, saves time and also helps in retention from formal learning [16].

\section{Team based learning}

In this approach of teaching, students are independent learners and they show an ability to work in a group. This also helps the instructor to identify and correct learning difficulties, of students on the spot. Students feel more responsible and are more engaged in this approach [17].

\section{N. Debate}

It is an active way of learning because it allows the the students to take a position, gather information to support their view and explain it to others. It encourages students to organize their thoughts in a critical or argumentative way that takes into account the complexity of the issues and existence of alternative and opposing views [18].

\section{O. Problem Based Learning}

Problem Based Learning (PBL) begun in 1950's as a movement to restructure medical school education. Unlike traditional instruction methodology that concludes in a problem after basic instruction on facts and skills, PBL begins with a problem, teaching facts and skills in relevant context. PBL is an approach which not only allows students to be an active participant in the learning process, but forces them to take an active role by engaging themselves in a meaningful, thought provoking way. PBL facilitates by giving students tools to become lifelong learners, tools that cannot be taught out of a text book, but only by being an integral part of the learning process. In PBL, students move away from following orders given by the instructor, to self-directed learning activities, from memorizing and repeating information to discovering information on their own. Students communicate and take responsibility for their learning instead of listening and reacting to lessons. PBL classrooms focus on the understanding of the processes instead of knowledge of facts, terms and content. Most importantly, PBL focus on lifelong learning [19].

\section{SYSTEM ANALYSIS AND DESIGN COURSE}

According to ACM [29], the IS curriculum is designed to educate graduates who are prepared to enter the workforce equipped with the knowledge and skills specified in three basic categories. They are (1) IS specific knowledge and skills, (2) Foundational knowledge and skills and (3) Domain fundamentals. The curriculum also includes seven major core courses that are 1) Foundations of Information Systems, 2) Data and Information Management, 3) Enterprise Architecture, 4) IS Project Management, 5) IT Infrastructure, 6) Systems Analysis \& Design, and 7) IS Strategy, Management, and Acquisition.
The System Analysis and Design (SAD) course discusses the processes, methods, techniques and tools that organizations uses to determine the various ways to conduct their business, with a particular focus. SAD covers a systematic methodology for analyzing a business problem or opportunity, determining what role, if any, computer-based technologies can play in addressing the business need, articulating business requirements for the technology solution, specifying alternative approaches to acquiring the technology capabilities needed to address the business requirements, and specifying the requirements for the information systems solution in particular, in-house development, development from third-party providers, or purchased commercial-o ff-the-shelf (COTS) packages [30].

\section{PBL AND SAD}

SAD is a complex course, which has diverse areas going from project management skills to communication, design and implementation expertise. It is not just a series of rules, regulations and procedures to be learnt, but a set of skills that must be acquired and practiced. In today's dynamically changing environment, it is no longer adequate, to simply teach the students the concepts of SAD, as its content and context will change drastically before students reach their first job. Students need to become lifelong learners in this era of software development. They need cognitive skills, critical thinking and problem-solving practice capabilities. Moreover, the large diversity of software design and development approaches as well as the accelerated development of new software technologies requires a continuous learning process. A highly effective way to achieve this is to get students to work on a problem which requires them to exercise these skills, exploit knowledge and acquire new information as needed. PBL is one of the teaching methodologies, in which students engage complex challenging problems and collaboratively work together to reach for solution. PBL is about students connecting disciplinary knowledge to real-world problems. The motivation to solve a problem becomes motivation to learn. PBL creates a learning environment in which teachers coach student's thinking and guide students inquiry, facilitating deeper levels of understanding. It organizes curriculum around a given holistic problem, enabling student learning in relevant and connected ways [20].

The main characteristics of PBL are [26]:

- Learning is student-centered.

- Learning occurs in small student groups.

- A tutor is present as a facilitator or guide.

- Authentic problems are presented at the beginning of the learning sequence before any preparation or study has occurred.

- The problems encountered are used as tools to achieve the required knowledge and the problem- 
solving skills necessary to eventually solve the problems.

- New information is acquired through self-directed learning.

To cope up with the ever changing market trend and requirement, students not only need to know about the subject and its content but also practical knowledge and experience are more important. Universities, who are the suppliers of the skilled labor to the market, have to include certain guidelines in the curriculum that will make student a lifelong learner.

\section{TEA CHING METHODOLOGIES AT KING ABDULAZIZ UNIVERSITY}

King Abdulaziz University (KAU) was established in 1967 as a national university aiming at spreading higher education in the western area of Saudi Arabia. KAU is considered as a pioneer in offering higher education for the Saudi students. The University not only has the regular students program, but it also has the external program to make it easy for all students to receive higher education. One of the long-term goals of the university is to develop and continuously improve student's performance standards that measure their academic levels and skills. KAU has different colleges under its umbrella, such as Faculty of Arts and Humanities, Faculty of Computing and Information, Faculty of Dentistry, Faculty of Eng ineering, Faculty of Economics \& Administration, Faculty of Marine Sciences, Women's Faculty of Design and Arts and many more [29].

Most of the faculty members at KAU use lecture as their basic mode of delivering information to the students. Classrooms are equipped with interactive smart boards that affect the students learning in positive ways. This inevitably raise the level of student engagement in classrooms, motivate students and promote enthusiasm for learning. Lectures involve the power point presentation as well as discussions and cooperative learning. However, the biggest disadvantages of lecture based approached observed is that students do not immediately observe the relevancy of the materials given to them in the class. They tend to frequently forget the information, especially after the final exam. Hence, the exposures to the materials do not assure knowledge transfer to courses later in their degree program. The concern is how to best provide information to the students so that they remember it and apply it not only in the upcoming semesters but also after graduation and thus integrate the knowledge they have gained down the years in their graduation, with the real world experience in their job environ ment.

\section{ACCREDITATION PROCESS}

KAU is undergoing a transformation to improve the quality of teaching and learning. Its aim is to achieve the accreditation from Accreditation Board for Engineering and Technology (ABET) for Faculty of Computing and Information \& Technology (FCIT). ABET promotes quality education and also innovations in the education [21]. ABET has modified their accreditation criteria to place an emphasis on PBL and self-directed learning which supports life-long learning. To meet ABET criteria, educational institutions nationwide have added problem based learning, project and design-based learning to their formal curricula. To act in accordance with ABET criteria of 2012, FCIT degree programs i.e., Information Systems, Computer Science and Information Technology, had formulated program educational objectives (PEOs), which are broad statements that describe what graduates are expected to attain within a few years of graduation. PEOs are based on the needs of the program's constituencies. PEOs address institutional and program mission statements and are responsive to the expressed interests of various groups of program stakeholders [22]. The assessment planning process of ABET includes a set of PEOs, Student Learning Outcomes (SLOs) and Course Learning Outcomes (CLOs) for each degree program.

\section{INFORMATION SYSTEMS PROGRAM AT KAU}

The graduate students of the Information Systems Program are expected to [27].

1. Work as integral part of the information field connecting people with information using technology.

2. Advance in their careers through knowledge of computer information systems, communication skills, and understanding of business and contemporary technological issues.

3. Contribute to the economic growth and the well fare of the Saudi society through the development and management of information systems for business and research.

\section{A. Student Learning Outcomes}

SLOs are defined as what students are expected to know and be able to do by the time of graduation. These relate to the knowledge, skills, and behaviors that students acquire as they progress through the program [26]. The following Table 1 lists the criterions that an IS Program must demonstrate and that graduates must have in accordance with ABET. The key SLO for Information System program is "J". 


\section{TABLE I. SLOS OF INFORMATION SYSTEMS PROGRAM}

\begin{tabular}{|l|l|}
\hline A & Apply knowledge of computing mathematics \\
\hline B & $\begin{array}{l}\text { Analyze problems, identify and define computing } \\
\text { requirements. }\end{array}$ \\
\hline C & $\begin{array}{l}\text { Design, implement \& evaluate systems, process, } \\
\text { component or program. }\end{array}$ \\
\hline D & Function effectively on teams. \\
\hline E & $\begin{array}{l}\text { Understanding of professionals, ethical, legal, } \\
\text { security and social issues. }\end{array}$ \\
\hline F & Communicate effectively with the range of audience. \\
\hline G & $\begin{array}{l}\text { Local and global impact of computing on individuals, } \\
\text { organization and society. }\end{array}$ \\
\hline H & Continuing professional development. \\
\hline I & $\begin{array}{l}\text { Current techniques, skills and tools necessary for } \\
\text { computing practice. }\end{array}$ \\
\hline J & $\begin{array}{l}\text { An understanding of processes that support the } \\
\text { delivery and management of information sy stems } \\
\text { within a specific application environment. }\end{array}$ \\
\hline
\end{tabular}

\section{B. Course Learning Outcomes for Information Systems Program}

A learning outcome is a written statement of what the successful student/learner is expected to be able to do at the end of the module/course [23]. There are three elements, which will lead to a successful course design. They are Learning Objectives, Assessment and Instruction. Learning objectives are written statement of what a student should get, out of a given learning experience. Instructions are the different modes of teaching that will be implemented so that student's objectives are attained successfully. Assessment is the process of evaluating the students to check and to make sure that the objectives are reached. These elements are inter-related components that are dependent on each other, but not necessarily in sequential order. These factors contribute to the students learning process. If the assessment factor does not show a satisfactory result, it means that the other two factors, learning objectives and instruction modes have to be changed, until the desired result is obtained.

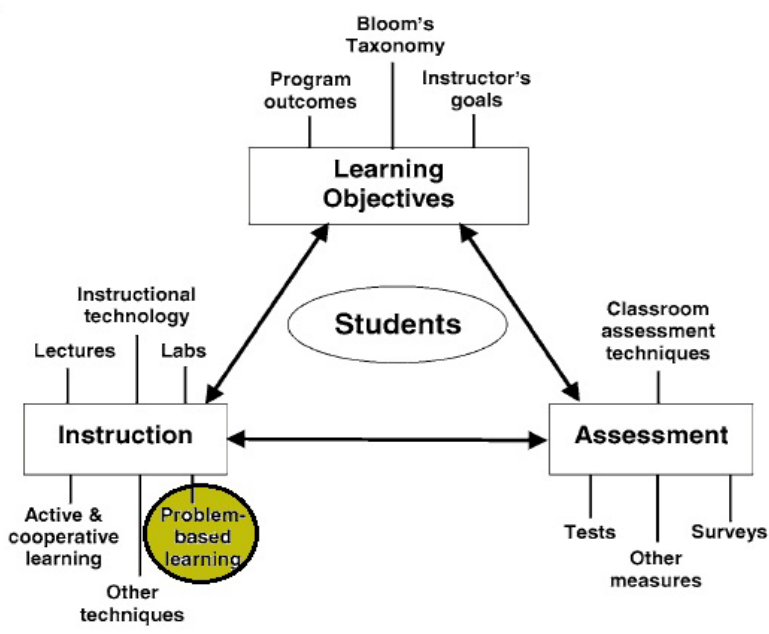

Figure 1. Elements of Course Design
Figure 1 depicts these elements [21]. In addition, Figure 1 also highlights PBL in the instruction element as one of the teaching methods. PBL is an essential technique, which guides the students from theory to practical journey of problem solving. PBL follows a constructivist perspective in learning, as the role of the instructor is to guide and challenge the learning process rather than strictly providing knowledge [24].

\section{SAD AT KAU}

SAD at KAU is taught at the senior level to the IS students as their core subjects. Software Engineering (CPIS-250) is the core subject for the SAD courses. This core subject is the baseline of the principle software development skills and prepares students for the upcoming SAD courses in the further semesters. The teaching of SAD course is spread in two semesters as System Analysis and Design I (CPIS-351) and System Analysis and Design II (CPIS-352). The pre-requisite for System Analysis and Design I (CPIS-351) is Software Engineering (CPIS-250). SAD courses normally establish the fundamental principles used in the disciple area and provide students with an opportunity to demonstrate their understanding through mini projects that run in the lab. It requires the use of various CASE tools, thus giving the students a chance to examine, practice, and demonstrate understanding of each phase in system analysis and design.

\section{SURVEY REQUIREMENT ANALYSIS}

A survey, tests and observations were conducted to study the adoption of PBL in SAD course. The requirement analysis is described as follows.

A total of 30 students, divided in two sections of 15 students each were taken under consideration. These students in turn were divided into groups of three. At the initial phase of the course short case studies were given to the students to achieve the task of the lecture. A total of five problems were given at different stages, to cover different topics of the first semester SAD courses. Problems were selected in such a way, that they cover certain topics of the course and identify the key concepts. The aim of the problems was to have students analyze the organization's problem, investigate approaches to understand and solve the problem. The students had to work on problems and reach solutions, in short frame of time. The students were not given any predetermined lectures, pre assigned readings to investigate these problems. Students were expected to investigate about the problem by themselves, discuss with their group mates and take help from the instructor if needed.

The following set of CLOs is chosen from the course CLOs.

1. Explain the elements of project management and responsibilities of a project manager. 
2. Explain project initiation and activities in the project planning phase of the SDLC.

3. Develop a cost/benefit analysis and assess the feasibility of a proposed project.

4. Explain why identifying use cases are the key to defining functional requirements.

5. Read, interpret, and create an entity-relationship diagram.

6. Identify and analyze data entities and doma in classes needed in the system.

These CLOs were achieved through PBL method, using different case studies with topics as follows:

1. Project Success and Failure factors.

2. Project Manager's skills.

3. Project Management activities.

4. Entity modeling involving different types of entities.

5. Events and Use cases identification in different problem do main areas.

To ensure about students view on PBL experience, respective feedback was taken from the students.

\section{SURVEY FINDINGS}

\section{A. Outcome of Survey}

A survey was conducted to check the overall students' satisfaction and their acceptance of PBL applied in the class. It was based on the 30 responses given by the student [28]. The outcomes are as follows.

1. The students have not taken any course with PBL approach before. They also agreed that it really helped them to understand practical knowledge of system development techniques applied in the real world problem. They were also of an opinion that the PBL approach gave them a chance to communicate with their peers and discuss the issues and arrive to a suitable decision.

2. $68 \%$ of the students were of the opinion that the problem given to them in the class helped them to gain practical knowledge of system analysis and design techniques.

3. $59 \%$ were of opinion that $\mathrm{PBL}$ approach has helped them to improve their ability to find, read and analyze information.

4. $68 \%$ strongly agreed that PBL class helped them to develop their reasoning process by posing questions, and challenging and critiquing information presented in the problem.

5. $62 \%$ preferred PBL class to a conventional (lecture based) class.

6. $68 \%$ strongly agreed that they actively participated in PBL class.

\section{B. Outcome of Tests}

A test was conducted in the class to evaluate the students understanding and success factor in the CLOs that were covered in the class using PBL. The five case studies that were given to the students come under the SLO "b", i.e., analyze a problem, identify and define computing requirement as in Table 1 . Table 2 shows the results of the test for 30 students from the two sections. The results show the students' achievement degree. It also demonstrates that students have more than $70 \%$ of grades, which is standard set by ABET, to measure students success factor.

TABLE II. TEST RESULTS

\begin{tabular}{|c|c|c|c|}
\hline \multicolumn{2}{|c|}{ Section I } & \multicolumn{2}{c|}{ Section II } \\
\hline Students & KSO-b/11 & Students & KSO-b/11 \\
\hline & & & \\
\hline 1 & 9.75 & 1 & 9.75 \\
\hline 2 & 7 & 2 & 10 \\
\hline 3 & 10.75 & 3 & 10 \\
\hline 4 & 10.5 & 4 & 9.5 \\
\hline 5 & 9.75 & 5 & 10.5 \\
\hline 6 & 9.5 & 6 & 9.75 \\
\hline 7 & 9.75 & 7 & 10.75 \\
\hline 8 & 10.75 & 8 & 10 \\
\hline 9 & 8.5 & 9 & 9.5 \\
\hline 10 & 10.25 & 10 & 9.75 \\
\hline 11 & 10.25 & 11 & 11 \\
\hline 12 & 10 & 12 & 10 \\
\hline 13 & 10.25 & 13 & 10.25 \\
\hline 14 & 9 & 14 & 9 \\
\hline 15 & 10.5 & 15 & 10.5 \\
\hline
\end{tabular}

\section{Outcome of Observations}

The adoption of PBL had been observed in the classroom. They are as the followings.

1. With PBL approach, students are the active participants and the lecturer is a facilitator rather than instructor. The students become the main area of focus. Thus, PBL can be called as a StudentCentered-Approach.

2. Student's decision making, is significantly improved and they were able to instantiate those decisions logically and with reasoning.

3. Students enjoyed the subject and had a feeling of satisfied learning.

4. Students developed a greater understanding of the subject topics and thus increased their knowledge and were more confident.

5. PBL enhances the learning of soft skills like communication, teamwork, which can be retained lifelong.

6. Students became comfortable working in teams, which is one of the key skills in the development process.

PBL also develops important skills in areas like creative insight, conflict resolution, higher reasoning, critical thin king, decision-making and problem solving [25]. 


\section{INFORMATION TRANSFER}

Based on the outcome of the survey, tests and observations in the class, this paper proposes a framework for effective PBL methodology that will successfully help in transferring the information from the lecturer to the student.

The framework constitutes of four major phases that are dependent on each other and are also individually responsible for the student's success. They are Problem Initiation, Discussions, Elicitations and Problem Representation.

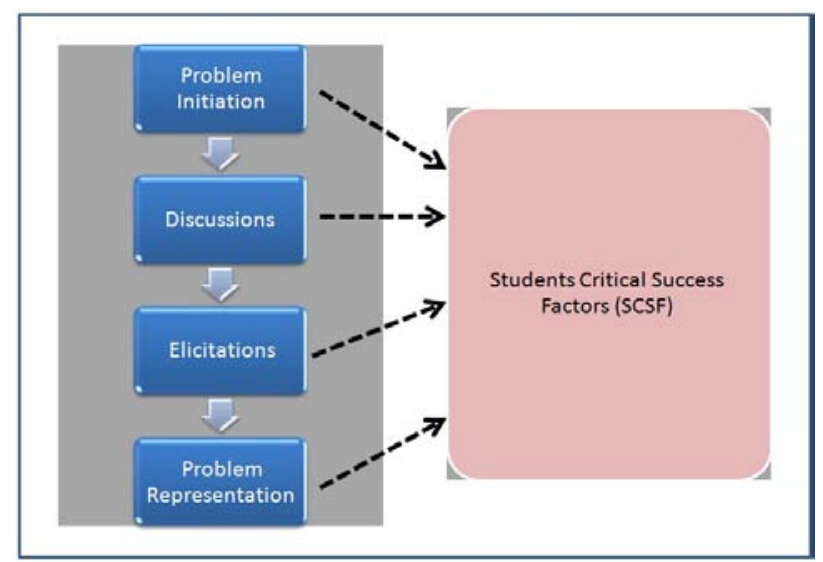

Figure 2. Information Transfer Framework

The first phase Problem Initiation starts when the problem to be investigated is identified and is given to the students, which is the most important and basic step. In this phase, utmost care is taken regarding the selection of problem. In this phase, the lecturer is a facilitator rather than an instructor.

The second phase Discussions is the process in which the information is transferred from the lecturer to the students in the form of discussions. This information transfer is also then done among the students, to increase the teamwork, which is one of the most important factors in PBL methodology. It can be also considered as a give-and-take relationship where the information is given and at the same also disseminated among the students. The information from this stage is mostly in the form of short notes, points or few highlighted words on which the discussions is continued. In this phase, the students actually explore the problem domain.

The third phase called Elicitations is the phase where the informal information is captured in the formal form, which is in knowledgeable form. In this phase, the students carry out the scientific resource findings among their peers.

The last phase called Problem Representation, is the phase in which the information and experience gathered from the above phases is converted into valuable knowledge by the students in terms of thinking, decision-making, learning and thus increasing the students' skills. Students put the information together and they present the findings for evaluations and ass essments.

The Students Critical Success Factor (SCSF) is the indicator of the students success, which is the aggregated result of all the above four factors.

The validation and verification of the proposed framework will be carried out and presented in the next stage of the study.

\section{CHA LLENGES IN IMPLEMENTING PBL}

Many challenges were faced while implementing PBL in SAD class. There are:

1. Selecting and designing good case studies is one of the most important aspects in SAD courses.

2. Language was a barrier; it takes lots of effort to explain students, different English terminology.

3. Students were not very much serious while giving feedback.

4. Some students were shy to indulge in group discussions and teamwork, thus one or two competent students lead the group where as the other members are passive.

5. A balance had to be maintained between the traditional lecture, lab practices and the PBL activities.

6. Lecturers need to more efforts with a positive attitude.

7. Assessing an individual student becomes difficult in PBL approach, as the most confident student only comes up with the final answers to the queries.

8. Building case studies customized to local cultural environment (with respect to KSA) is another challenging issue. Most all the case studies are based in regarding with the UK or USA environment.

\section{CONCLUSIONS}

The result of the survey was very encouraging for the use of PBL classes in SAD courses. PBL is gaining importance as the market, increasingly are demanding professionals that are able to develop team-integrated work. These paradigms have been proven to provide benefits in the learning of many of the soft skills required. The idea of replacing five lectures, i.e. onehalf hour each, with five PBL approach classes proved to be a successful one. The students enjoyed working on the problem given in the class and accepted the idea of PBL as a successful approach to learn the SAD courses. It has created a positive impact of learning among students. Large numbers of students were of the opinion that PBL class should be combined with the conventional class for better results. PBL methodology can be effectively applied to achieve the ABET criteria.

PBL also helps in avoiding cheating among the students, since different problems are given to each group. An effective PBL curriculum will not only help 
the students to progress through the course, but also try to develop and enhance skills like effective communication and teamwork, which will help them when they are in the working environment. It is also recommended to include some questions in the final assessment which are related to the real-life experience of analyst, so that the students can be individually examined.

Finally, in order to successful adoption of PBL, the faculty members should be given training to use PBL effectively and transfer the knowledge in their core courses.

\section{REFERENCES}

[1] Barrows, H.S. and Tamblyn, R.M, Problem-based learning: An approach to medical education. New York: Springer Publishing Company, Inc, 1980.

[2] Delisle, R, "How to Use Problem-Based Learning in the Classroom: Why use Problem Based Learning in Classroom?" Association of supervision and curriculum development (ASCD). Pp. 13, 1997.

[3] Moust, J. H. C, Berkel, H. J. M. V and Schmidt, H. $\mathrm{G}$, "Signs of erosion: Reflections on three decades of problem-based learning at Maastricht University,” Higher Education, vol. 50, no. 4, pp. 665-683, 2005.

[4] Richardson, Ita, "Problem Based Learning in the Software Engineering Classroom", 22nd Conference on Software Engineering Education and Training, 2009.

[5] UCI, “Problem-Based Learning Faculty Institute”. http://www.pbl.uci.edu/whatispbl.html, retrieved on February 12, 2012.

[6] Lori A. Cascone, "Teaching Strategies", Retrieved on 5th March 2012 from http://station05.qc.ca/css/cybersite/reachout/strategies/teaching.htm, 2012

[7] Bruffee, K. A, Collaborative learning: Higher education, interdependence and the authority of knowledge. Baltimore, The Johns Hopkins University Press, 1993.

[8] Gilbert, S. W, "Why distance education?" A special bulletin. American Association for Higher Education, 48, 1995.

[9] Moore, Joi L, Dickson-Deane. C and Galyenb .K , " e-Learning, online learning, and distance learning environments: Are they the same?" Internet and Higher Education 14, 2011.

[10] Brent. R, Felder, Richard. M, "Active Learning: An Introduction”. ASQ Higher Education Brief, 2009.

[11] Lai, Emily. R, " Critical Thinking: A Literature Review", Pearson's Research Reports, 2011.

[12] Bhat. Vasant. D, Experiential Learning: A Handout for Teacher Educators, Regional Institute Of Education,Mysore.

http://wikieducator.org/images/b/b5/EXPERIENTIA L_LEA RNING.pdf Retrieved on 15th March 2012.

[13] Klassen. Kenneth J, Willoughby. Keith, "In-Class Simulation Games: Assessing Student Learning".
Journal of Information Technology Education. Volume 2, 2003.

[14] Mihalcea. R, Strapparava. C, "Learning to laugh (automatically): Computational models for humor recofnition.” Computational Intelligence, Volume 22, Number 2, 2006.

[15] Alberta Learning, Focus on Inquiry: A teacher's guide to implement Inquiry-based learning, 2004.

[16] Woodill. G, The Mobile Learning Edge: Tools and Technologies for Developing Your Teams, McGraw-Hill, 2010.

[17] Connell. Robert. M,. " Adapting Team-Based Learning to Early Engineering Courses". Proceedings of the 2011 Midwest Section Conference of the American Society for Engineering Education, 2011.

[18] Kennedy. R, "In-Class Debates: Fertile Ground for Active Learning and the Cultivation of Critical Thinking and Oral Communication Skills". International Journal of Teaching and Learning in Higher Education. Volume 19. 2007.

[19] Utecht. R. Jeffery, Problem-Based Learning in the Student Centered Classroom, 2003.

[20] Torp, L., \& Sage, S, Problems as Possibilities: Problem-Based Learning for $k-16$ Education (2 ed.). Alexandria, WA: Association for Supervision and Curriculum Development., 2002.

[21] ABET, "ABET Vis ion and Mission", Retrieved February 27, 2012 from http://www.abet.org/visionmission/.

[22] Felder, R.M., and R. Brent, “Designing and Teaching Courses to Satisfy the ABET Engineering Criteria," Journal of Engineering Education, Vol. 92, No. 1, pp. 7-25, 2003.

[23] Adam, S., "Using Learning Outcomes: A consideration of the nature, role, application and implications for European education of employing 'learning outcomes' at the local, national and international levels". United Kingdom Bologna Seminar 1-2 July 2004, Heriot-Watt University (Edinburgh Conference Centre) Edinburgh. Scotland, 2004.

[24] Hmelo-Silver and Barrows, S. "Goals and Strategies of a Problem-based Learning Facilitator", Interdisciplinary Journal of Problem-based Learning, Volume1, Issue 1, Article 1, 2006.

[25] INTEL, Coorporation, Intel ${ }^{\circledR}$ Teach Program, Designing Effective Projects: Characteristics of Projects Benefits of Project-Based Learning, 2007.

[26] Barrows, H. S, Problem-based learning in medicine and beyond, In L. Wilkerson \& W. H. 1996.

[27] ABET, (2011). Program Criteria for Information Systems and Similarly Named Computing Programs, Retrieved February 27, 2012 from http://www.abet.org/DisplayTemplates/DocsHandb ook.aspx?id=3138.

[28] Sara Fatima, PBL (2) Survey form for Problem Based Learning methodology, Retrieved December 23, 2012 from 
https://docs.google.com/spreadsheet/gform?key=0A g3IrIcW my6QdHkySGtiNHh5SmIPVXZOeEZLN WctLUE\&gridId $=0$ \#chart.

[29] ACM and AIS, IS2010 Curriculum Guideline for Undergraduate Degree Programs in Information Systems. 2012.

[30] Mohammed Abdullah Nassef, "King Abdulaziz University”. 2011. Retrieved 1 June 2013 from http://nasseef.info/king_abdulaziz_university.

Sara Fatima is a Lecturer at Faculty of Computing and Information Technology (FCIT), King Abdulaziz University (KAU), Jeddah, Saudi Arabia. She teaches subjects like Software Engineering, IS Analysis and Design, and IS Design and Implementation, under the Department of Information System. She has attained her Master's Degree from Muffakham Jah College of Engineering \& Technology (M.J.C.E.T) Os mania University, Hyderabad, India.

Salha Abdullah is an Assistant Professor at Department of Information Systems, Faculty of Computing and Information Technology, King Abdulaziz University, Jeddah, Saudi Arabia. She teaches Database, System Analysis and Design, E-Business Systems, and Project Management. She received her $\mathrm{PhD}$ in Process and Information Modeling. She is a member of Association for Information Systems. 